\title{
IS DRY REFORMING THE SOLUTION TO REDUCE NATURAL GAS CARBON FOOTPRINT?
}

\author{
BRUNA REGO DE VASCONCELOS \& JEAN-MICHEL LAVOIE \\ Industrial Research Chair on Cellulosic Ethanol and Biocommodities (CRIEC-B), \\ Department of Chemical and Biotechnological Engineering, \\ Université de Sherbrooke, Sherbrooke, Canada.
}

\begin{abstract}
With the increasing world's energy demand along with the constantly expanding field of natural gas exploitation around the world, dry reforming of methane has gained increasing attention. Through this technology, natural gas can be converted into syngas, which is a well-known building block used for the production of alcohols and fuels. This technology has become an interesting approach for the valorization of a variety of $\mathrm{CO}_{2}$ streams and for the reduction of the natural gas carbon footprint. In this work, attention will be given to the different reforming technologies used at industrial scale, followed by an investigation of the different approaches used for dry reforming of methane. Furthermore, focus will be given on how natural gas reforming could be used as a vehicle to store renewable energy while trying as well to reduce the carbon footprint of this technology. The technology presented in this work was previously developed by Hydro Québec and uses a cheap and available catalyst in addition to electricity to convert methane and carbon dioxide into syngas. Reactants conversions were up to $99 \%$ and the syngas produced had a $\mathrm{H}_{2} / \mathrm{CO}$ ratio of 1 for over $200 \mathrm{~h}$.

Keywords: dry reforming, electricity, heterogeneous catalyst, natural gas, syngas.
\end{abstract}

\section{INTRODUCTION}

Following the COP21 conference in Paris in 2015, most of the world leading economies are seriously considering the possibility to reduce GHG emissions, which, in turn, requires lowering the utilization of fossil fuel. In Canada as an example, the federal government has a strong commitment in reducing GHG emissions throught an approach reported in the PanCanadian Framework on Clean Growth and Climate Change [1]. The main objective of this framework is to reduce by 2030 the country's GHG emission 30\% below 2005 levels. This corresponds to about 525 Megaton eq. $\mathrm{CO}_{2}$ per year for the whole country, which per capita corresponds to about 15 tonne per inhabitant. In order to reach this target, the approach will be to put a price on carbon and of course on $\mathrm{CO}_{2}$ emissions either through a carbon tax or using a cap-and-trade system. As an example, the minimum value of carbon should be of 10 $\$(\mathrm{CAN})$ per tonne in 2018 moving up to 50\$(CAN) per tonne in 2022. Canada has the advantage of having abundant natural resources including but not limited to biomass and hydroelectricity. This abundancy in natural resources has logically an impact on the price paid by the general public and the price of electricity in Quebec (one of Canada's province) is actually $0.0582 \$ / \mathrm{kWh}(\mathrm{CAN})$ [2] for residential uses while it goes as low as $0.0327 \$$ / $\mathrm{kWh}$ for industrial uses [3]. On the other side of the Atlantic Ocean, the European Union has committed towards reducing its GHG emissions 40\% below 1990's level corresponding to 3,441 Megaton eq. $\mathrm{CO}_{2}$ per year [4], which in turn represents 4.63 tonne per inhabitant per year. In 2015, the average price for electricity at household level was, in average, $0.22 €$ / $\mathrm{kWh}$ and about $0.125 € / \mathrm{kWh}$ at industrial level [5].

Hence, despite the very variable commitments from the different government toward reducing GHG emissions, there is a general global tendency towards reduction of GHG emissions, which will require a significant reduction of fossil fuel utilization in order to materialize. 
One possible approach to reach such a goal would be to replace large portions of fossil fuel consumption by renewable electricity or by renewable carbon-based substrates. As far as heating and cooling building is concerned, a careful utilization of renewable electricity is of course to be considered. However, some of the technologies allowing production of renewable electricity are constrained by peak periods during the day. Technologies such as solar or wind power are often more efficient during peak periods of the day making them a very variable and less reliable source to provide a steady energy source to large agglomerations. Hydroelectricity is of course a very stable source of renewable electricity although only available in large amounts in selected places around the world. Hence, in some cases, electricity is abundant and reliable, while for others it is a constant problem since it is necessary to cope for the periods during which electricity is less abundant (as an example during nighttime for solar energy). Another option would be to eventually cope for the lower electricity production period by using other technologies such as thermal plants operating on biomass CHP. However, biomass is not necessarily abundant everywhere and there is a strong necessity to secure a stable supply before relying on such option. Co-firing biomass with coal is another possibility although may cause some issues with regards to GHG emissions, especially if a reduction of carbon footprint is considered. Furthermore, adding more biomass to the electricity production may become especially challenging if transportation fuels also rely on this renewable carbon resource.

While the public and government's awareness and action towards global warming and GHG emissions increase on one side, the amount of fossil fuel being produced and consumed around the planet (and especially natural gas) is also significantly increasing. From 1990 to 2014, the world production of natural gas increased from 2457 to 4073 Billion cubic meter, which corresponds to an increase of about $166 \%$ in 30 years. Consumption of natural gas increased as well significantly over the last decades ranging from 52,944 Bcf in 1980 up to $122,804 \mathrm{Bcf}$ in 2014 corresponding to an increase of more than a twofold in about 40 years. North America is the biggest consumer on the planet with 33,279 Bcf (about 25\% of the consumption) followed by Asia and Oceania (24,737 Bcf). The latter has shown a very significant increase over the last 40 years ranging from 2,576 Bcf in the 80's up to a tenfold in the last couple of years. Among the different zones in the world, the only one that recorded a decrease in the last years was Europe while all the other regions of the world reported increase in consumption. As far as $\mathrm{CO}_{2}$ emissions are concerned, natural gas consumption has led to the production of 6,983 MMTons $\mathrm{CO}_{2}$ in 2014, which once again represents more than a twofold as compared to the production of $\mathrm{CO}_{2}$ associated with the consumption of natural gas in 1980 [6].

Hence, there is on one side a significant interest and commitment from government and populations alike to favor sustainability and reduce GHG while the world's energy demand is increasing as well as fossil fuel exploitation. In many locations around the globe, natural gas has become one of the cheapest sources of carbon at this time (3.162 USD/GJ - May 2017) and with the actual reserves estimated to $6,879 \mathrm{Tcf}$ in 2016 , there is no doubt about the fact that this source for energy will be staying in the global portfolio for the years to come. Natural gas has been reported by many in open literature as a source of fossil carbon with a lower impact on carbon footprint $[7,8]$ but can this carbon balance be improved?

The world's energy is hence facing two problems and one of the best ways to address such a situation would be to combine both in order to create a new opportunity. On one hand, there is the abundancy of renewable energy that is either available at specific locations around the globe (such as in Quebec) or available in large amounts in specific time of the day such as 
wind and solar power. Such energy cannot, at this point, be efficiently stored in large scale in batteries although conversion to chemicals (such as hydrogen) may be considered. On the other hand, there is this wide interest towards natural gas that led to the constantly expanding field of natural gas exploitation around the world.

This work will hence focus on how natural gas reforming could be used as a vehicle in order to store renewable energy while trying to reduce the carbon footprint of such technology as well. Going through a process called Dry Reforming (DR), natural gas could be reacted with carbon dioxide originating from renewable carbon sources (such as first or second-generation ethanol processes) to produce syngas. The latter could downstream be used as a building block for fuels and chemicals. Such technology could as well be used as a storage system for renewable electricity since dry reforming is a highly endothermic reaction in addition to the fact that the syngas produced from this process has a low hydrogen to carbon monoxide ratio.

\section{REFORMING TECHNOLOGIES}

Environmental issues along with the increasing production and consumption of natural gas have raised questions on how to efficiently use this resource. Reforming of natural gas is a technology fully developed at industrial scale and used for syngas production. Among the reforming technologies, there are four main process to consider: steam reforming (SRM), partial oxidation (POX), autothermal reforming (ATR) and dry reforming (DRM). These technologies differ in the type of oxidizing agent used and in the $\mathrm{H}_{2} / \mathrm{CO}$ ratio of the syngas produced.

Steam reforming of natural gas or steam reforming of methane (SRM) is the leading industrial process for natural gas reforming and for hydrogen and methanol production [9-11] and $80 \%-85 \%$ of the global hydrogen production is done through this process [9]. SRM is an endothermic reaction, which requires steam as oxidizing agent and produces a syngas with a $\mathrm{H}_{2} / \mathrm{CO}$ ratio of 3 (eqn 1). This process is performed in multiple steps. In the first step, methane reacts with steam in two different reformers at temperatures between $800^{\circ} \mathrm{C}$ and $1000^{\circ} \mathrm{C}$ and at pressures around 15-30 atm. Despite being favored at low pressures, $\mathrm{H}_{2}$ plants require the product at high pressures [12]. Catalysts employed in this step are mostly nickel-based catalysts. Then, the $\mathrm{H}_{2} / \mathrm{CO}$ of the syngas produced in the first step is increased via water-gas shift reaction (WGS) (eqn 2) in two other reformers using an iron and copper-based catalysts. The products of the WGS reaction are then separated and purified. Under stoichiometric conditions ( 1 mol of water per mol of methane), carbon deposition is thermodynamically favored. So, steam is usually fed in excess with $\mathrm{H}_{2} \mathrm{O} / \mathrm{CH}_{4}$ around 2.5-3. However, it has an impact on the overall cost of the process since steam generation requires significant amounts of energy [13].

$$
\begin{gathered}
\mathrm{CH}_{4}+\mathrm{H}_{2} \mathrm{O} \rightleftarrows \mathrm{CO}+3 \mathrm{H}_{2} \Delta \mathrm{H}_{298 \mathrm{~K}}^{\circ}=206 \mathrm{~kJ} / \mathrm{mol} \\
\mathrm{CO}+\mathrm{H}_{2} \mathrm{O} \rightleftarrows \mathrm{CO}_{2}+\mathrm{H}_{2} \Delta \mathrm{H}_{298 \mathrm{~K}}^{\circ}=-41 \mathrm{~kJ} / \mathrm{mol}
\end{gathered}
$$

Despite being a well-established technology, continuous improvement such as materials for reformer, catalyst performance and process concepts have resulted in reforming plants with lower investments and operational costs [12].

Partial oxidation of natural gas (POX) is an exothermic reaction that uses oxygen as oxidizing agent. In addition, such process usually requires a low energy investment when compared to SRM. In this process, methane reacts with oxygen to produce syngas with a $\mathrm{H}_{2} / \mathrm{CO}$ ratio of 2 (eqn 3 ). 


$$
\mathrm{CH}_{4}+\frac{1}{2} \mathrm{O}_{2} \rightleftarrows \mathrm{CO}+2 \mathrm{H}_{2} \Delta \mathrm{H}_{298 \mathrm{~K}}^{\circ}=-38 \mathrm{~kJ} / \mathrm{mol}
$$

POX can be performed catalytically with nickel-based catalysts or non-catalytically. In the latter case, it requires high temperatures $\left(1300^{\circ} \mathrm{C}-1400^{\circ} \mathrm{C}\right)$ to achieve high conversions. Catalytical POX has the advantage of operating at lower temperatures and contact times, which implies small reactors with fast start-ups [14]. Nevertheless, the exothermicity of the combustion reaction limits the application of this process. Hot spots may be formed along the catalytic bed, which can provoke catalyst deactivation. Moreover, severe problems related to heat management and safety can also occur [12].

Authothermal reforming (ATR) is an approach resulting from the combination of SRM (eqn 1) and POX (eqn 3). First, natural gas is mixed with oxygen within a burner where POX takes place to provide heat for the reforming reaction. However, using pure oxygen would substantially increase the overall cost of the process hence, a mixture of oxygen, steam and/ or $\mathrm{CO}_{2}$ with methane is usually used [15]. Then, in the same reformer, steam and/or $\mathrm{CO}_{2}$ react with the fuel remaining from the POX reaction to produce syngas. High temperatures between $1000^{\circ} \mathrm{C}$ and $1200^{\circ} \mathrm{C}$ are required to avoid the formation of byproducts. Therefore, part of the methane invested in the process is used for heating.

Dry reforming of natural gas or dry reforming of methane (DRM) has been considered as an alternative approach for syngas production from natural gas. This process (eqn 4) has gained increased attention since two main greenhouse gases, methane $\left(\mathrm{CH}_{4}\right)$ and carbon dioxide $\left(\mathrm{CO}_{2}\right)$, are converted into syngas at a $\mathrm{H}_{2} / \mathrm{CO}$ ratio of 1 [12]. However, occurrence of simultaneous reverse water-gas shift reaction (RWGS) (eqn 5) may lead to a $\mathrm{H}_{2} / \mathrm{CO}$ ratio lower than 1.

$$
\begin{gathered}
\mathrm{CH}_{4}+\mathrm{CO}_{2} \rightleftarrows 2 \mathrm{CO}+2 \mathrm{H}_{2} \Delta \mathrm{H}_{298 \mathrm{~K}}^{\circ}=247 \mathrm{~kJ} / \mathrm{mol} \\
\mathrm{CO}_{2}+\mathrm{H}_{2} \rightleftarrows \mathrm{CO}+\mathrm{H}_{2} \mathrm{O} \Delta \mathrm{H}_{298 \mathrm{~K}}^{\circ}=41.2 \mathrm{~kJ} / \mathrm{mol}
\end{gathered}
$$

Among the reforming technologies, DRM is the reaction requiring the largest amount of energy and oxidation of natural gas is the method usually employed at industrial scale to cover the energy requirements of the reaction. However, using renewable energy, such as electricity would decrease $\mathrm{CO}_{2}$ emissions from the combustion of fossil fuel and would be a way of chemically store renewable energies, which is a challenge nowadays due to the intermittence of this type of energy.

Despite the environmental advantages and in contrast to the other reforming technologies, DRM is not fully applicable at industrial scale yet due to high energy requirements, fast deactivation of the commercial catalysts under the reaction conditions and requirement of a pure and steady source of $\mathrm{CO}_{2}$ [15]. The CALCOR process (Caloric $\mathrm{GmbH}$ ) and SPARG process (Haldor Topsøe) are two commercial technologies based on DRM reaction but are usually combined with SRM or POX in order to operate under milder conditions and to adjust $\mathrm{H}_{2} / \mathrm{CO}$ ratios $[12,16]$.

\section{REFORMING AND DRY REFORMING CATALYST}

The most common way to lower the DRM energy demand to activate the reaction is the use of heterogeneous catalysts. However, the catalysts generally used in DRM suffers from fast deactivation mostly due to sintering in the high temperatures of reaction and carbon deposition via side reactions, such as methane cracking (eqn 6) and Boudouard reaction (eqn 7). 


$$
\begin{gathered}
\mathrm{CH}_{4} \rightleftarrows \mathrm{C}_{(\mathrm{s})}+2 \mathrm{H}_{2} \Delta \mathrm{H}_{298 \mathrm{~K}}^{\circ}=75 \mathrm{~kJ} / \mathrm{mol} \\
2 \mathrm{CO} \rightleftarrows \mathrm{C}_{(\mathrm{s})}+\mathrm{CO}_{2} \Delta \mathrm{H}_{298 \mathrm{~K}}^{\circ}=-171 \mathrm{~kJ} / \mathrm{mol}
\end{gathered}
$$

Transition metals-based catalysts ( $\mathrm{Ni}, \mathrm{Fe}, \mathrm{Co} . .$.$) and noble metals-based catalysts have been$ investigated for this reaction. Noble metals-based catalysts such as $\mathrm{Pt}, \mathrm{Ru}, \mathrm{Rh}$ and $\mathrm{Pd}$ have shown to be highly active in DRM reaction with good resistance against carbon formation. Rostrup-Nielsen et al. [17] compared the activity of different noble metals ( $\mathrm{Rh}, \mathrm{Ru}, \mathrm{Pt}$ and $\mathrm{Pd}$ ) and Ni supported on $\mathrm{MgO}$. They reported the following order of performance: $\mathrm{Ru}>\mathrm{Rh}$ $>\mathrm{Ni}>\mathrm{Ir}>\mathrm{Pt}>\mathrm{Pd}$. They showed that the rate of carbon formation was much lower for the noble metals-based catalyst than for the $\mathrm{Ni}$ catalyst, especially at $500^{\circ} \mathrm{C}$, temperature at which carbon forming reactions are favored. Similarly, Coronel et al. [18] tested $0.6 \mathrm{wt} \% \mathrm{Rh} /$ $\mathrm{La}_{2} \mathrm{O}_{3}-\mathrm{SiO}_{2}$ catalyst in the DRM reaction for over $180 \mathrm{~h}$ of time on stream. The catalyst was highly active and stable and no carbon formation was detected. Ballarini et al. [14] investigated the performance of a platinum catalyst with metal loadings varying between $0.02,0.1$ and $0.5 \mathrm{wt} . \%$. They observed that methane conversion increased with platinum content. After $135 \mathrm{~min}$ of reaction, significant deactivation was observed for the catalysts containing 0.02 and $0.1 \mathrm{wt} \%$ Pt. However, analysis of the spent catalysts showed negligible carbon contents, suggesting that the deactivation was provoked by sintering of the platinum particles.

Despite their good performance, the costs of noble metals catalysts are much higher than the transition metals catalysts, which hinders their utilization at large scale. In addition, transition metals-based catalysts, especially nickel, have a history in the field of reforming and especially for SRM processes. Li et al. [19] investigated the effect of Ni contents from 2 to $20 \mathrm{wt} . \%$. They showed that the performance of the catalyst gradually increased with Ni loadings from 2 to $10 \mathrm{wt}$ \%. However, further increase led to loss in catalytic stability mostly due to increase in the size of nickel particles and to carbon deposition. Similarly, Kroll et al. [20] investigated the performance of $\mathrm{Ni} / \mathrm{SiO}_{2}$ catalyst on $\mathrm{DRM}$ at $700^{\circ} \mathrm{C}$. The catalyst showed an initial methane conversion around $80 \%$, that decreased to about $70 \%$ in the first hours of reaction and remained stable for $80 \mathrm{~h}$ of time on stream. The initial deactivation was related to nickel particles sintering and coke deposition.

So, the longevity of the catalyst has become a crucial parameter in the approach of using heterogeneous catalysts to lower the DRM energy demand to activate the reaction. In order to improve coke resistance of transition metals-based catalysts, dopants to increase basicity and consequently carbon removal and improve metal dispersion over the support have been investigated. Therdthianwong et al. [21] tested the effect of $\mathrm{ZrO}_{2}$ on the performance of $\mathrm{Ni} /$ $\mathrm{Al}_{2} \mathrm{O}_{3}$ catalyst. They reported that $\mathrm{ZrO}_{2}$ addition enhanced the dissociation of $\mathrm{CO}_{2}$ forming oxygen intermediates, which improved gasification of coke deposits. Similarly, Alipour et al. [22] investigated the influence of alkaline and alkaline-earth promoters such as $\mathrm{BaO}, \mathrm{CaO}$ and $\mathrm{MgO}$ on the performance of $\mathrm{Ni} / \mathrm{Al}_{2} \mathrm{O}_{3}$ catalyst during $\mathrm{DRM}$ at $700^{\circ} \mathrm{C}$. They reported that the addition of the promoters enhanced the basic properties of the catalysts and consequently favored $\mathrm{CO}_{2}$ adsorption, which resulted in higher coke resistance.

\section{USE OF RENEWABLE ELECTRICITY - THE HQ-UDES PROCESS AND SCALE-UP}

Many approaches have been reported so far in literature when it comes to dry reforming of methane or short chain alkanes. Many of the researches published in open literature reports on the utilization of classical nickel-based catalyst in a fixed bed reactor. However, other reports aim at the utilization of different system and in some cases, involving electricity. 
Tu et al. reported on the dry reforming of methane using a classical nickel on gamma-alumina catalyst but with a plasma [23]. For the experiments, the authors developed a coaxial dielectric barrier discharge (DBD) reactor that they operated at atmospheric pressure. The results showed that a combination of the higher power level used in this experiment combined with the lower debit allowed an optimal conversion of methane and carbon dioxide into syngas. The gas flow used in this work however was of $50 \mathrm{~mL} / \mathrm{min}(25 \mathrm{~mL}$ of both reactant) for an optimal power requirement of $50 \mathrm{~W}$. Hence the power requirement is about 3 times the total power value of the methane being processed through the reactor which, combined to the complexity of the custom-made plasma reactor may inhibit the possibility to scale such technology at larger scale.

Sekine et al. also investigated the effect of electricity on the dry reforming reaction using a non-equilibrium electric discharge at ambient temperature [24]. In this specific case, the interest was for biogas, which in most cases has a composition comparable to what is required for state of the art dry reforming reactions. Another important factor of this work is that the reaction was performed at ambient temperature, which is quite uncommon for dry reforming reactions that are known to operate at high temperatures. The system was found very effective for $\mathrm{H}_{2} \mathrm{~S}$ conversion at low power input. As far as methane conversion was concerned, the work reported a total of $1.2 \mathrm{~W}$ power input for a total conversion of $60 \%$ of methane. If compared to the previous work, the total flow rate for the biogas was $10 \mathrm{cc} / \mathrm{min}$; hence, in this case the power required for the conversion of biogas was $37 \%$ the calorific value of the methane injected in the reactor leading to a conversion of a little more than half the methane being injected in the reactor. Despite the fact that the system, as the one reported by Tu et al., may be hard to scale-up, there is nevertheless an undeniable potential for conversion of $\mathrm{H}_{2} \mathrm{~S}$ that reached in some cases close to $90 \%$. For this specific work, no catalyst was reported and the composition of the electrodes was not specified to the best of our knowledge.

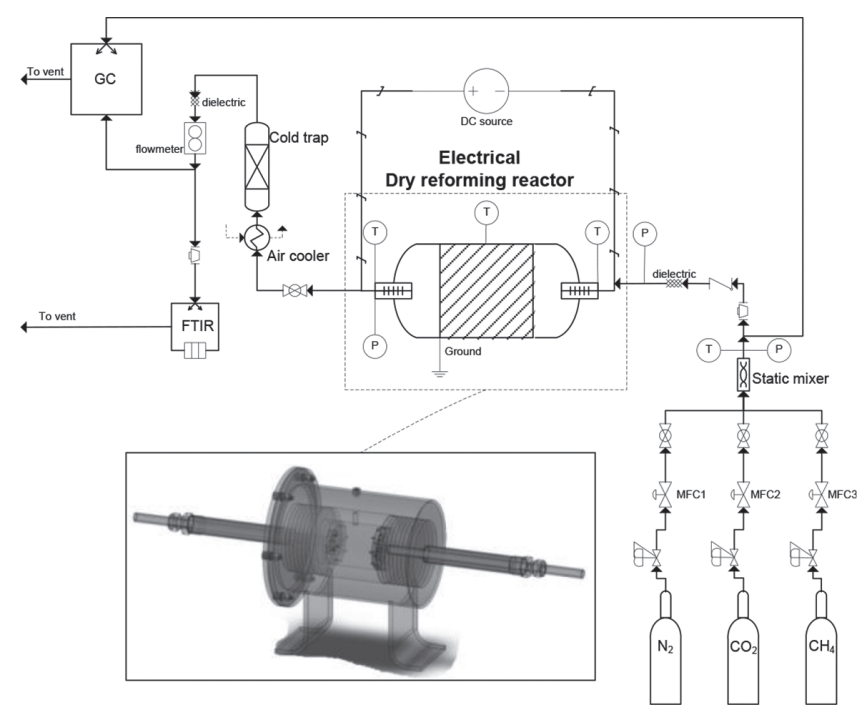

Figure 1: Original configuration of the electrically-activated dry reforming reactor as reported by Banville et al. [26]. 
Another conversion approach that was reported in literature for dry reforming of methane was reported by Labrecque and Lavoie in 2011. In this work, the authors claimed that the utilization of an electrified fixed bed of steel wool allowed high conversions both of methane and of carbon dioxide [25]. This approach could possibly lead to new and disruptive innovations in the field since it used a catalyst that was not extensively reported in that field before and a reactive system that was overall complex although simpler and cheaper to scale than the plasma-based systems. The authors reported on a $343 \mathrm{~W}$ consumption of electrical current for an overall conversion close to $70 \%$ of the methane and $\mathrm{CO}_{2}$ entering the reactor. However, the feed of methane was reported to be $1.70 \times 10^{-4} \mathrm{~mol} / \mathrm{s}$ of methane, which makes the power required for the conversion significantly higher than the amount of energy originally fed in the reactor (via the calorific value of methane). Although at this point energetically unfavorable, the concept behind de reactor was slightly simpler with a common catalyst (steel wool bought at the hardware store and sandwiched between two electrodes (Fig. 1).

Later, the same authors reported on another system conceptually quite comparable to the one reported in Fig. 1 except for the outside design of the reactor that was this time made of

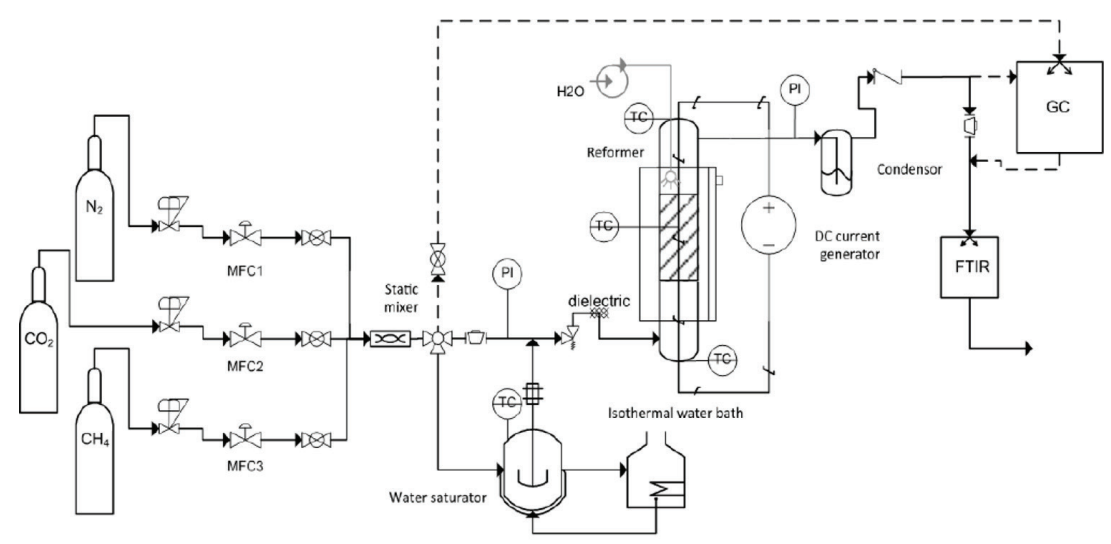

(a)

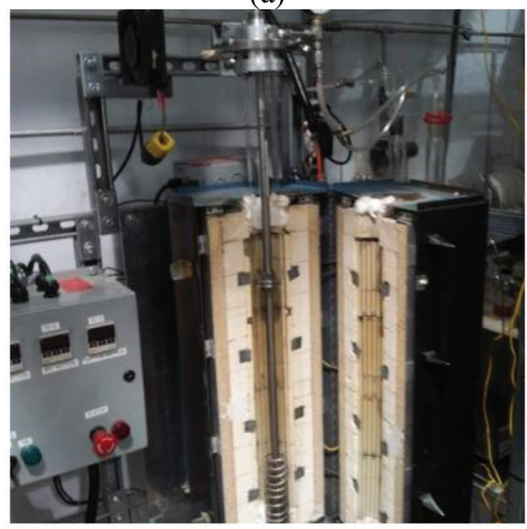

(b)

Figure 2: Configuration of the second generation of the electricity-activate dry reforming reactor where $(\mathbf{A})$ is the P\&ID of the overall system and $(\mathbf{B})$ shows a picture of the reactor. 
quartz instead of steel. In addition, the reactor in this case was also externally heated using a tubular furnace contrarily to the system reported in Fig. 1. Figure 2A shows the general P\&ID of the modified reactor [27] while Fig. 2B shows a picture of the system.

From the second generation of catalyst and following an optimization of the different parameters, the team was able to reduce the amount on energy invested in the system while increasing the conversion both of methane and carbon dioxide. Hence, the team was able to reach total conversion of both reactant with a power investment of $65 \mathrm{~W}$ using a GHSV of $3200 \mathrm{~h}^{-1}$ corresponding to a total inlet flow of about $1 \mathrm{~L} / \mathrm{min}$ at $950^{\circ} \mathrm{C}$. In terms of energy requirement, the amount of electricity invested in this case corresponded then to about $20 \%$ of the value of methane injected in the reactor. While reducing the amount of electricity invested, the team pursued their work on this technology and are now completing the

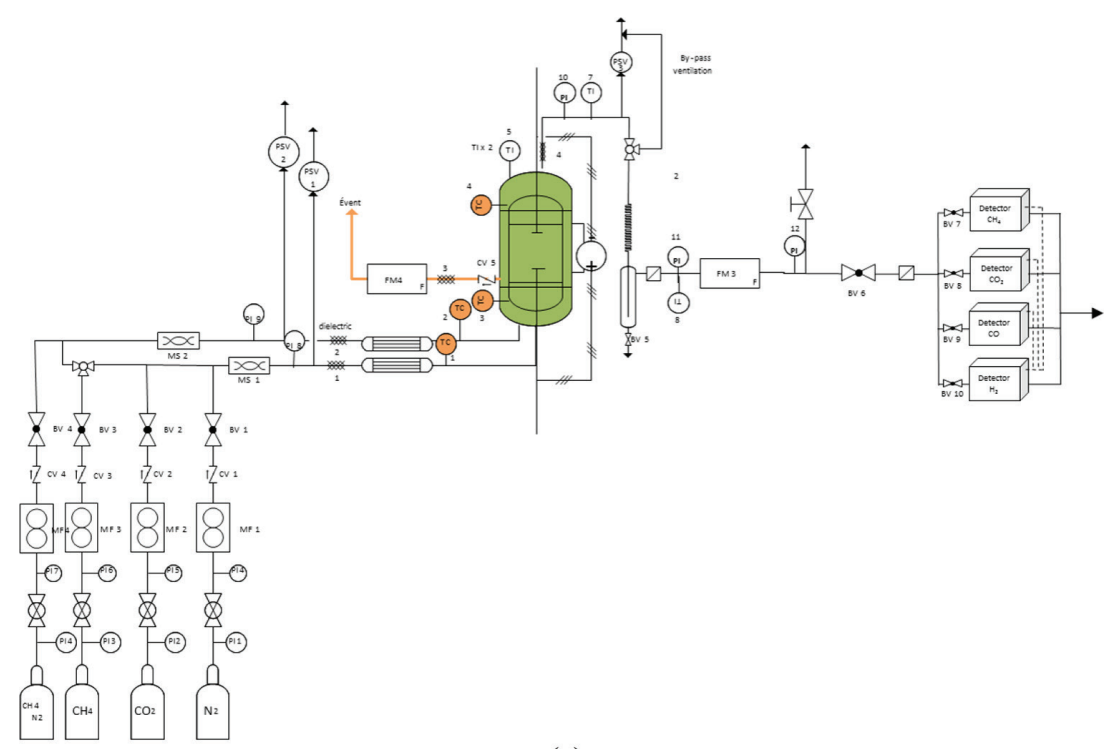

(a)

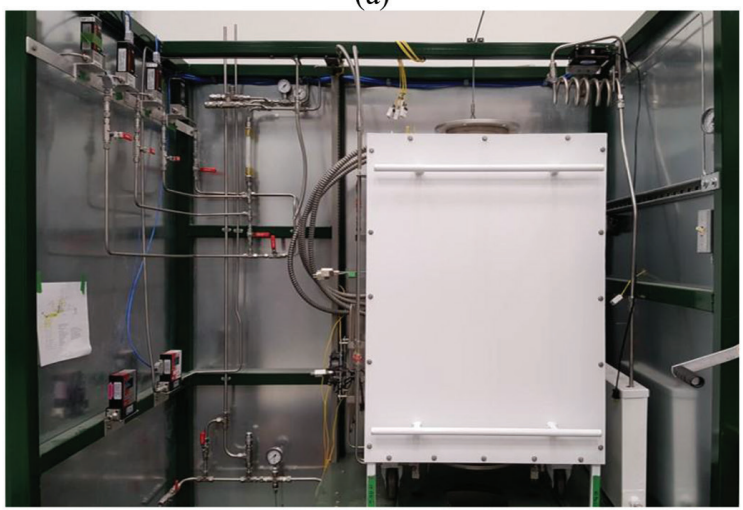

(b)

Figure 3: Configuration of the pilot scale reactor with a capacity of $40 \mathrm{~L} / \mathrm{min}$ where $(\mathbf{A})$ is the P\&ID of the overall system and (B) shows a picture of the reactor. 
assembly of a pilot scale reactor with a capacity of $40 \mathrm{~L} / \mathrm{min}$. The technology now relies on one patent and one patent pending process and should be compatible for natural gas, biogas and tail gas. Figure 3 depicts the P\&ID of the scaled-up system and a picture of the most recent advances.

\section{MASS \& ENERGY BALANCE - ECONOMICAL POTENTIAL}

As mentioned earlier, dry reforming is a process by which carbon dioxide is reacted with methane in order to produce two moles of carbon monoxide as well as two moles of molecular hydrogen (eqn 4). Using dry reforming instead of classical reforming will involve sequestration of 1 mole of $\mathrm{CO}_{2}$ per mole of methane reacted. Since carbon dioxide has a higher molar mass than methane and it is required to react 1 mole of methane per mole of carbon dioxide, a tonne of carbon dioxide will permit conversion of about $364 \mathrm{~kg}$ of methane. If this reality is considered from the methane perspective, it means that, in order for the dry reforming process to be efficient at a $1 / 1$ ratio between the two gases it will require 2.7 metric tonne of $\mathrm{CO}_{2}$ to react with one tonne of methane. Hence dry reforming of one tonne of methane could lead to the sequestration of almost 3 tonnes of carbon dioxide.

In Canada, carbon dioxide is expected to worth in the range of 50\$ per tonne in 2022 [1]; hence, utilization of $\mathrm{CO}_{2}$ in a dry reforming process could provide additional benefits of $135 \$(\mathrm{CAN})$ per tonne of methane converted. In provinces such as Quebec (Canada), the price of electricity for industrial application is of $0.0327 \$(\mathrm{CAN})$ per $\mathrm{kWh}$ (hence for 3600 $\mathrm{kJ})$. As mentioned earlier, dry reforming is an endothermic process that requires in the range of $247.3 \mathrm{~kJ} / \mathrm{mol}$ to be performed. Hence, each tonne of methane converted should require $4214 \mathrm{kWh}$ to be converted to syngas, which would overall represent at the above reported price a cost of about $138 \$(\mathrm{CAN})$ per tonne of methane converted using dry reforming, which is about the same amount of money that would be generated from the carbon credits on $\mathrm{CO}_{2}$.

If such situation was to be compared with steam reforming of methane, and assuming a scenario where the price of methane would remain the same (2.85 USD/GJ - June 2017), the first target would be to assess on the price required for the conversion of one tonne of methane considering the endothermicity of this reaction as well. The steam methane reforming has an endothermic value of $206.8 \mathrm{~kJ} / \mathrm{mol}$ and the calorific value of methane is $55530 \mathrm{~kJ} / \mathrm{kg}$. Hence, one tonne of methane $\left(55.7 \times 10^{7} \mathrm{~kJ}\right)$ would require $1.29 \times 10^{7} \mathrm{~kJ}$ for the endothermic part of the steam reforming reaction, which correspond roughly to $23.2 \%$ of the energy value of methane dedicated to cope for the thermodynamics of the reaction. This would overall represent an investment of 12.9 GJ per tonne of methane converted, which, according to the prices mentioned above, would represent an investment of $49.53 \$$ (CAN) to convert one tonne of methane. Hence, in 2022 if both electricity and methane remains at the same price as they are right now and that the price of $\mathrm{CO}_{2}$ have reached $50 \$(\mathrm{CAN})$ per tonne, conversion of natural gas with a combination of renewable $\mathrm{CO}_{2}$ and electricity would be more economical than classical steam reforming.

In order to break even with the actual price of natural gas and using renewable electricity from Quebec at industrial rate, a break-even scenario between the price invested for the thermodynamics of both process would be when the price of $\mathrm{CO}_{2}$ would be in the range of $20-30 \$(C A N)$ per tonne, which is envisioned to be in 2020-2021 [1]. In such scenario, the endothermic penalty of dry reforming would cost about the same as the one for steam methane reforming. All these calculations remain speculations but overall, it is clear that there is 
progressively room for processes such as dry reforming and that on the strict economical point of view, there might be in a near future and in specific location around the globe (such as in Quebec) the possibility to get such technologies at industrial level. Of course, other considerations will have to be considered, such as the reduction of the carbon footprint of dry reforming technologies as well as being able to produce a new 50/50 renewable/fossil variety of fuels and chemicals (or 75/25 on mass basis).

\section{CONCLUSIONS}

Dry reforming technologies could be a very disruptive technology that could allow solving two problems by combining them into a sole opportunity. With the recent withdrawal of the US from COP21 (June 2017), and since the US is one of the biggest users of natural gas around the planet, there is no doubt that this form of fossil fuel will be sticking around for the upcoming decades. Reforming can be performed with different kind of oxidants ranging from the highly exothermic reactions obtained with air or pure oxygen to the endothermic reactions obtained when using steam and carbon dioxide. While steam methane reforming offers the advantage of producing a hydrogen-rich syngas, dry reforming (that uses $\mathrm{CO}_{2}$ as oxidant) has the advantage of using another GHG, and depending from the source of this carbon dioxide, such an approach could be very beneficial in a world where carbon footprint is becoming a global concern. Using carbon dioxide, as an example, from first or second biofuel process could lead to a net reduction of natural gas carbon footprint and overall decrease the impact related to this fossil fuel and its ever-expanding exploitation and market. Since dry reforming involves an equimolar reaction between carbon dioxide and methane and assuming a renewable source of $\mathrm{CO}_{2}$ (such as $\mathrm{CO}_{2}$ from fermentation) the overall carbon footprint of methane on a strict molecular footprint would decrease by $50 \%$.

Still in accordance with the objectives of COP21, one of the main challenges on a global scale is to reduce the production of electricity being produced from fossil fuel. Hence, production of renewable electricity can be done using different process such as (but not limited to) wind power, solar power, biomass cogeneration and hydroelectricity. In many cases however there is either a punctual excess or an overall excess of such energy and always remains the challenge of storing this energy in light of future utilizations. From this reality has developed the concept of e-fuels where renewable electricity is used to transform $\mathrm{CO}_{2}$ into fuels or chemicals (such as methane of methanol). In reactions such as reforming (steam or dry) both reactions are very energy intensive in light of very endothermic processes. In order to cope for the system's demand in energy, renewable electricity could be used to heat reactions hence coping for this thermodynamic penalty. In common reforming systems such as steam reforming technologies, the energy requirement of the reaction is covered by the utilization of part of the natural gas (or methane) that is fully oxidized to produce the energy required by the process. Hence, by using electricity it allows reducing combustion of fossil fuel and overall the carbon footprint of this technology.

Combining both renewable $\mathrm{CO}_{2}$ and renewable electricity in dry reforming process would overall significantly reduce the carbon footprint of natural gas exploitation and utilization in the field of fuels and chemicals synthesis. In this work was reported the first process relying on the combined utilization of renewable carbon dioxide and electricity. The UdeS process allows conversion of methane and carbon dioxide up to $99 \%+$ into a syngas with a $\mathrm{H}_{2}: \mathrm{CO}$ ratio of 1 . This technology, originally developed by Hydro Quebec, relies on a cheap and available catalyst (Bulldog steel wool) and has been scaled from laboratory to pilot scale. Such technologies, allying the concept of e-fuels to fossil fuel, could represent a game 
changer in the upcoming years since they allow renewable energy storage combined to positively impacting the carbon footprint of natural gas. However, dry reforming also leads to a low hydrogen content as compared to most of the reforming technologies on the market. It is nevertheless possible to increase the hydrogen content in the syngas by adding renewable hydrogen produced from the electrolysis of water into the process, which could allow displacing again fossil fuels. It now seems clear that many solutions are available and the upcoming challenges for engineers and scientist will be to take such concept and make them reach a full industrial scale. Costs will necessarily be an issue, although carbon credits combined with a strong determination from governments to push forward GHG reduction technologies to make of this era one of the most suitable for changes.

\section{ACKNOWLEDGEMENTS}

The authors would like to acknowledge contribution from the BioFuelNet network (Gasification project work package) as well as MITACS for Dr Bruna Rego de Vasconcelos postdoctoral fellow grand. The authors would also like to acknowledge the original sponsors of this work (Enerkem, Hydro Quebec and CRB Innovations) as well as NSERC. Finally, the authors would like to acknowledge the sponsors of the Industrial Research Chair on Cellulosic Ethanol and Biocommodities for their contribution to this work.

\section{REFERENCES}

[1] Government of Canada, PAN-CANADIAN FRAMEWORK on Clean Growth and Climate Change, 2017.

[2] Hydro Québec, Tarif D - Tarif domestique pour la clientèle résidentielle et agricole, (n.d.). Available at: http://www.hydroquebec.com/residentiel/espace-clients/compte-etfacture/comprendre-facture/tarifs-residentiels-electricite/tarif-d.html.

[3] Hydro Québec, Tarif L - Tarif industriel pour la clientèle de grande puissance, (n.d.). Available at: http://www.hydroquebec.com/grandesentreprises/tarification/tarifsgrande-puissance/tarif-1/ (accessed June 6, 2017).

[4] European Commission, Eurostat - Statistics Explained. Total greenhouse gas emissions by countries, 1990-2014. (n.d.). Available at: http://ec.europa.eu/eurostat/statistics-explained/index.php/File:Total_greenhouse_gas_emissions_by_countries_(including_international_aviation_and_indirect_CO2,_excluding_LULUCF),_1990_-_2014_(million_tonnes_of_CO2_equivalents)_updated.png (accessed June 6, 2017).

[5] European Commission, Eurostat - Statistics Explained. Electricity and gas prices, second half of year, 2013-2015 (n.d.). Available at: http://ec.europa.eu/eurostat/statisticsexplained/index.php/File:Electricity_and_gas_prices,_second_half_of_year,_201315_(EUR_per_kWh)_YB16.png (accessed June 6, 2017).

[6] U.S. Department of Energy, International Energy Statistics, (n.d.). Available at: https:// www.eia.gov/beta/international/data/browser/index.cfm\#/?pa=0000000000000000000 04\&tl_id=3002-A\&vs=INTL.3-6-AFRC-TCF.A\&cy=2014\&vo=0\&v=H\&start=1980 (accessed June 6, 2017).

[7] U.S. Department of Energy, International Energy Outlook 2016 - Chapter 3. Natural gas, 2016. Available at: https://www.eia.gov/outlooks/ieo/nat_gas.cfm (accessed June 6, 2017).

[8] ICF Consulting Canada, Life Cycle Greenhouse Gas Emissions of Natural Gas - A Literature Review Of Key Studies Comparing Emissions From Natural Gas and Coal, pp. 1-8, 2012. Available at: http://www.capp.ca/getdoc.aspx?DocId=215278. 
[9] Alhamdani, Y.A., Hassim, M.H., Ng, R.T.L. \& Hurme, M., The estimation of fugitive gas emissions from hydrogen production by natural gas steam reforming. International Journal of Hydrogen Energy, 42(14), pp. 9342-9351, 2017.

https://doi.org/10.1016/j.ijhydene.2016.07.274

[10] Anzelmo, B., Wilcox, J. \& Liguori, S., Natural gas steam reforming reaction at low temperature and pressure conditions for hydrogen production via Pd/PSS membrane reactor. Journal of Membrane Science, 522, pp. 343-350, 2017.

https://doi.org/10.1016/j.memsci.2016.09.029

[11] Johnson Matthey, Reforming (ATR, GHR, SMR), (n.d.). Available at: http://www. jmprotech.com/core-technologies-reforming-ATR-GHR-SMR.

[12] Ferreira-Aparicio, P., Benito, M.J. \& Sanz, J.L., New trends in reforming technologies: from hydrogen industrial plants to multifuel microreformers. Catalysis Reviews, 47(4), pp. 491-588, 2005.

https://doi.org/10.1080/01614940500364958

[13] Darujati, A.R.S. \& Thomson, W.J., Kinetic study of a ceria-promoted catalyst in drymethane reforming. Chemical Engineering Science, 61(13), pp. 4309-4315, 2006. https://doi.org/10.1016/j.ces.2006.02.007

[14] Ballarini, A., Basile, F., Benito, P., Bersani, I., Fornasari, G., De Miguel, S., Maina, S.C.P., Vilella, J., Vaccari, A. \& Scelza, O.A., Platinum supported on alkaline and alkaline earth metal-doped alumina as catalysts for dry reforming and partial oxidation of methane. Applied Catalysis A: General, 433-434, pp. 1-11, 2012.

https://doi.org/10.1016/j.apcata.2012.04.037

[15] Lavoie, J.M., Review on dry reforming of methane, a potentially more environmentallyfriendly approach to the increasing natural gas exploitation. Frontiers in Chemistry, 2, pp. 1-17, 2014. https://doi.org/10.3389/fchem.2014.00081

[16] Jafarbegloo, M., Tarlani, A., Mesbah, A.W. \& Sahebdelfar, S., Thermodynamic analysis of carbon dioxide reforming of methane and its practical relevance. International Journal of Hydrogen Energy, 40(6), pp. 2445-2451, 2015. https://doi.org/10.1016/j.ijhydene.2014.12.103

[17] Rostrup-Nielsen, J.R. \& Hansen, J.H.B., CO2 reforming of methane over transition metals. Jouranl Catalysis, 144(1), pp. 38-49, 1993.

https://doi.org/10.1006/jcat.1993.1312

[18] Coronel, L., Múnera, J.F., Lombardo, E.A. \& Cornaglia, L.M., Pd based membrane reactor for ultra pure hydrogen production through the dry reforming of methane. Experimental and modeling studies. Applied Catalysis A: General, 400(1-2), pp. 185-194, 2011. https://doi.org/10.1016/j.apcata.2011.04.030

[19] Li, L., Zhang, L., Zhang, Y. \& Li, J., Effect of Ni loadings on the catalytic properties of $\mathrm{Ni} / \mathrm{MgO}(111)$ catalyst for the reforming of methane with carbon dioxide. Journal Fuel Chemistry and Technology, 43(3), pp. 315-322, 2015. https://doi.org/10.1016/S1872-5813(15)30007-4

[20] Kroll, V.C.H., Swaan, H.M., Lacombe, S. \& Mirodatos, C., Methane reforming reaction with carbon dioxide over Ni/SiO2Catalyst. Journal of Catalysis, 164(2), pp. 387-398, 1997. 
[21] Therdthianwong, S., Siangchin, C. \& Therdthianwong, A., Improvement of coke resistance of Ni/A12O3 catalyst in $\mathrm{CH} 4 / \mathrm{CO} 2$ reforming by $\mathrm{ZrO} 2$ addition. Fuel Processing Technology, 89(2), pp. 160-168, 2008. https://doi.org/10.1016/j.fuproc.2007.09.003

[22] Alipour, Z., Rezaei, M. \& Meshkani, F., Effect of alkaline earth promoters (MgO, CaO, and $\mathrm{BaO}$ ) on the activity and coke formation of Ni catalysts supported on nanocrystalline Al2O3 in dry reforming of methane. Journal of Industrial Engineering Chemistry, 20(5), pp. 2858-2863, 2014. https://doi.org/10.1016/j.jiec.2013.11.018

[23] Tu, X. \& Whitehead, J.C., Plasma-catalytic dry reforming of methane in an atmospheric dielectric barrier discharge: understanding the synergistic effect at low temperature. Applied Catalysis B: Environmental, 125, pp. 439-448, 2012. https://doi.org/10.1016/j.apcatb.2012.06.006

[24] Sekine, Y., Yamadera, Y., Matsukata, M. \& Kikuchi, E., Simultaneous dry reforming and desulfurization of biomethane with non-equilibrium electric discharge at ambient temperature. Chemical Engineering Science, 65(1), pp. 487-491, 2010. https://doi.org/10.1016/j.ces.2009.06.011

[25] Labrecque, R. \& Lavoie, J., Dry reforming of methane with CO2 on an electronactivated iron catalytic bed. Bioresource Technology, 102, pp. 11244-11248, 2011. https://doi.org/10.1016/j.biortech.2011.09.088

[26] Banville, M., Lee, R.A., Labrecque, R. \& Lavoie, J.M., Interaction of CO2/CH4 with steel wool in an electrocatalytic dry reforming reactor. Energy and Sustainability IV, 176, pp. 17-28, 2013. https://doi.org/10.2495/ESUS130021

[27] Banville, M., Labrecque, R. \& Lavoie, M.J., Dry reforming of methane under an electro-catalytic bed: effect of electrical current and catalyst composition. Energy and Sustainability V, 186, pp. 603-611, 2014. https://doi.org/10.2495/ESUS140531 